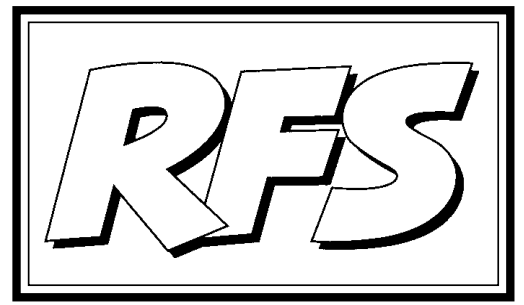

Revista de Fomento Social, 54 (1999), 245-259

\title{
Las contradicciones de Kosovo
}

Tras una estancia de varias semanas en un campo de refugiados kosovares de Kukes (Albania) en el marco del Servicio Jesuita a Refugiados, el autor nos resume sus impresiones y reflexiones sobre la guerra de Kosovo y la situación resultante en la región. Viniendo de un testigo presencial de lo que ha ocurrido sobre el terreno, estas reflexiones adquieren mayor valor y constituyen una denuncia que esperamos no pase desapercibida.

\section{Juan A. ESTRADA DÍAZ S.J. (*)}

La guerra de Kosovo ha terminado. Pocas veces hemos encontrado tan dividida a la opinión pública. Representantes de la izquierda que defendían los bombardeos y personas caracterizadas por su conservadurismo que los criticaban; políticos que defendían a Milosevic, al que presuntamente se agredía por ser de izquierdas, y otros que lo comparaban con Hitler; lamentaciones comunes por las víctimas kosovares que daban origen a acusaciones dispares, tanto contra la OTAN como contra el régimen serbio. El viejo problema de si hay una guerra «justa» ha cobrado

(*) Profesor de la Facultad de Filosofía y Letras de la Universidad de Granada. 
nueva fuerza a la luz de la expulsión y retorno de los kosovares. Una vez concluido el conflicto armado ha llegado el momento de hacer un balance. Se han planteado así problemas diversos aunque conectados, el de la justificación o no de la guerra, el de la situación de los refugiados en los campamentos y el del regreso de los deportados con los problemas que quedan pendientes. Veamos cada uno de estos tres apartados.

\section{1. ¿Se puede justificar la guerra de Kosovo?}

La guerra de Kosovo arroja una novedad que ha sido muy discutida. Se trata de una intervención armada contra un Estado que no ha agredido a otro, sino que ha perseguido a una parte de su población, violando masivamente los derechos humanos y restringiendo casi al límite los derechos políticos de esos ciudadanos. De ahí, el enfrentamiento entre los que defienden la soberanía nacional y que se trata de un asunto «interno» y los que apoyan el derecho de intervención o de injerencia humanitaria y la soberanía «limitada». Hay aquí un paso más en una línea que también se ha seguidoen el casoPinochet. Cuando se violan masivamente los derechos humanos, de forma constante, reiterada e indiscriminada no hay soberanía nacional válida. El derecho a intervenir está por encima de la soberanía nacional y los que detentan el poder del estado no pueden estar exentos de rendir cuentas por la conculcación permanente y masiva de los derechos del hombre. Al contrario, un estado que conculca la dignidad humana de forma reiterada y masiva pierde legitimidad. Los dictadores ya no pueden dormir tranquilos refugiados en la impunidad política estatal. Esto es lo que está cambiando poco a poco en el derecho internacional, adecuando la legalidad vigente a las exigencias éticas, corresponsabilizando a todos los estados y universalizando los derechos del hombre.

Desde estaperspectiva, hay una legitimación inicial del derecho de intervención. No cabe duda de que en Kosovo ha habido una conculcación masiva de los derechos políticos de los ciudadanos desde 1990, la imposición de una minoría (la serbia) contra la mayoría de la población albano-kosovar (un 80\% del total) y la preparación de un plan de depuración del territorio que ha originado en un par de meses la expulsión de casi un millón de personas. Todos los datos que se van conociendo avalan la tesis de que el éxodo kosovar no fue una improvisación 
casual, sino resultado de una planificación premeditada y pensada. La propaganda occidental, que compara a Milosevic con el régimen nazi, tiene desgraciadamente una base fáctica clara y tangible. El régimen combinó un nacionalismo exasperado con una ideología racista y denigratoria de los derechos del hombre.

Los problemas, sin embargo, permanecen. Las cosas no están tan claras cuando se pregunta quién debe ejercer el derecho de intervención y cómo debe ejercerse. Es evidente que la OTAN, organización militar oficialmente defensiva, no tiene competencias para erigirse en juez y fiscal, al mismo tiempo, para acabar siendo ejecutora de la sentencia que ella misma ha pronunciado. Aquí comienza el cuestionamiento de la intervención militar. Es la ONU y no la OTAN la que debía intervenir y pronunciarse. La agresión armada de la OTAN, así como los pronunciamientos posteriores respecto a futuras vigilancias y misiones de «paz» por parte de la organización militar, no sólo violan la carta de la misma OTAN, sino la de las Naciones Unidas. La OTAN no intervino en las guerras de secesión yugoeslava: ni en la de Eslovania y Croacia, alentadas por algunos países de la organización, como, por ejemplo, Alemania, ni en la posterior de Bosnia, hasta que la situación se estabilizó, tras una larga y cruenta guerra. Tampoco intervino cuando los croatas recuperaron en 1995 la Krajina, región de mayoría serbia, y provocaron el exilio masivo de unos 200.000 serbios. Se prefirió callar, como se guardó silencio inicial ante los abusos de Milosevic (desde comienzos de los noventa), al que se veía como un pacificador y un interlocutor válido de Occidente.

De ahí que surja inevitablemente una doble ilegitimidad. Ni la OTAN es la que debe intervenir, ni ha actuado por igual en todas las ocasiones. Se puede argüir, con razón, que la ONU no podía intervenir porque lo impedía el derecho de veto que podía ejercer Rusia y la misma China. Y es verdad, pero no se dice que Estados Unidos, Inglaterra y Francia, que han sido los líderes indiscutibles de la guerra de la OTAN son los primeros que se niegan a reformar la carta de las Naciones Unidas, a eliminar el derecho de veto y a supeditar el derecho de intervención a un tribunal internacional (La Haya, otro organismo creado para ello o la misma asamblea de las Naciones Unidas). La política de los líderes occidentales, comenzando por Estados Unidos, es la de utilizar a la ONU cuando les conviene, sin reconocerle ningún derecho internacional al que tengan que someterse. Por eso, la reforma de la ONU estábloqueada por los líderes de la OTAN, y no sólo por Rusia y China, a los que se acusa ahora. De esta forma, el recurso fáctico a la OTAN viene exigido 
por la impotencia de la ONU, fruto de decisiones políticas que corresponden al final de la segunda guerra mundial, pero que han quedado obsoletas y desbordadas en la situación actual.

A esto hay que añadir el problema de la proporcionalidad entre lo que ocasiona la guerray lo que se sigue de ella. El derecho de intervención sólo en casos extremos puede traducirse en una acción militar y tiene muchos pasos intermedios. Hoy sabemos que la CIA advirtió al gobierno norteamericano de que un ataque aéreo agudizaría la «limpieza étnica» que se quería evitar (1). La retirada de observadores internacionales, periodistas y representantes de ONG y asociaciones internacionales ayudó al régimen de Milosevic, en lugar de frenar la política que habíainiciado. Se prefirió laintervención militaren lugarde un aislamientopolítico, cultural, económico, etc. (como por ejemplo, se hizo con Sudafrica) y, sobre todo, se vació Kosovo de testigos extranjeros, que eran los que más podían impedir la limpieza étnica con sus informaciones a la opinión internacional. De esta forma, el remedio fue peor que la enfermedad. En lugar de evitar la limpieza étnica la radicalizó, la apresuró y la universalizó. La guerra fue ineficaz para una de las metas que se pretendía (evitar la deportación masiva de los kosovares).

A esto se añadió un nuevo costo que al comienzo no se dijo: había que evitar a toda costa muertos de la OTAN. Esta ha sido la primera guerra ganada sin que haya habido ni enfrentamiento de tropas, ni ningún soldado de la OTAN muerto en combate. De esta forma, se hacía más aceptable una guerra poco popular en amplios sectores de la opinión pública. El precio a pagar todos lo conocemos: para evitar el derribo de aviones aliados ha habido que bombardear a gran distancia de Yugoslavia y Kosovo, con lo que se hacía más difícil distinguir entre objetivos militares y civiles. De esta forma ha habido un elemento perverso: ausencia de bajas militares de la OTANe incremento progresivo de pérdidas de vidas humanas civiles, así como una destrucción masiva de la infraestructura de los países bombardeados. Se ha destruido Kosovo, al que se quería liberar, juntamente con Yugoslavia, y se ha inaugurado un nuevo tipo de guerra, como ocurrió con el bombardeo de Guernica, en la que la indefensa población civil es la que lleva la peor parte, al contrario que con el concepto tradicional de «guerra justa». Asistimos a una nueva forma de entender la guerra, que es compatible con las estadísticas de popularidad de los gobernantes ante la opinión pública. Es un mal

(1) Remito a la detallada referencia que ofrece el editorial de Mientras tanto 74 (1999) 3-19. 
presagio para el futuro y un acicate para que el oportunismo político se imponga a las consideraciones morales.

El gran negocio que es la guerra, con la consiguiente satisfacción de los países productores de armas (todos los líderes de la OTAN y Rusia), así como el robustecimiento de la hegemonía norteamericana en Europa y en el mundo, son también efectos «colaterales» de esta pretendida «guerra justa», inevitablemente impregnada de intereses y estrategias muy lejanas a los debates éticos, humanistas y solidarios que la propaganda ha puesto en primer plano. No hay que olvidar que al final los pretendidos fines humanitarios de la guerra habían pasado a un segundo plano, y que lo que se planteaba sobre todo era una cuestión política: el triunfo o el fracaso de la OTAN, un resultado que afianzara su prestigio. Sólo en función de ello se planteó la posibilidad de enviar tropas terrestres, nunca para acortar el tiempo de guerra y el sufrimiento de la población kosovar.

La propaganda occidental se refugió en el eufemismo de «víctimas colaterales» para encubrir una forma nueva y distinta de hacer la guerra, en la que no importaba el número de víctimas serbias y kosovares con tal que no hubiera muertos aliados. Y es que no todos los muertos cuentan lo mismo para la opinión pública. Esto es lo que hizo que se alargara la guerra más de dos meses, en contra de las cuentas anteriores, que se generalizara la destrucción de Yugoslavia y Kosovo, que han retrocedido más de cuarenta años, y que se multiplicaran las víctimas civiles que sufrían tanto la persecución serbia como los bombardeos de la OTAN. El que los serbios se rebelaran contra esto y se vengaran masivamente en los desvalidos kosovares es también parte del coste de la liberación. Es el precio a pagar para que no haya ataúdes norteamericanos ni occidentales. Los muertos los ponen ellos. ¡ Y sigue habiendo gente que entiende esta guerra en términos maniqueos, en los que unos son los malos y otros los buenos, sin matices ni distingos!

\section{La situación de los refugiados}

Si la OTAN fue incapaz de impedir la limpieza étnica, eléxodo de los refugiados y la destrucción de Kosovo, no lo fue a la hora de acogerlos y de instalarlos en los refugios que se crearon para ellos. Cuando se compara la situación de los exilados kosovares con las de otros refugiados (como los saharauis, los de la región de los grandes lagos en Africa, los de las guerras de Indochina o los mismos palestinos 
o kurdos) se puede hablar de que han sido «refugiados de lujo». En un tiempo récord se crearon grandes campamentos, unos oficiales y supervisados por las Naciones Unidas, por ACNUR (Alto Comisionado de las Naciones Unidas para los refugiados), otros que surgieron de forma más descontrolada, a veces anárquica, bajo el patrocinio de alguna ONG o por iniciativas personales. En conjunto, sobre todo en los campamentos oficiales amparados por gobiernos, los refugiados han tenido asegurada la supervivencia y mucho más. Comida, agua y electricidad, seguridad y protección en los campos, asistencia humanitaria y cultural, etc. No hay que olvidar, sin embargo, que los refugiados llegaban a veces en situaciones penosas, desnutridos y afectados por la expulsión, que fue bastante apresurada. Otra situación distinta ha sido la de los que han vivido en campamentos improvisados, a veces erigidos de forma desorganizada y con medios insuficientes, y sin el respaldo de alguna institución seria que garantizara la supervivencia. Es ahí donde más se ha vivido en situaciones de penuria, con escasa infraestructura sanitaria e higiénica, y con gran escasez de recursos.

Ciertamente, hay que distinguir también entre los refugiados de los campos y los que se encontraban alojados en familias albanesas, que han sido los más desasistidos, los no controlados y los que más han sufrido mayores malos tratos e inseguridad, y a veces, abusos por parte de sus anfitriones y precios abusivos por la estancia en sus casas. La relación entre los albaneses y los kosovares ha estado llena de contradicciones y paradojas. Por un lado, hubo una gran generosidad y receptividad de los primeros respecto de los refugiados. Por otro lado, pronto comenzaron las tensiones, sobre todo al captar que los recursos de los kosovares y su anterior nivel de vida es superior al albanés, lo cual propició situaciones abusivas por parte de algunas familias anfitrionas respecto de los refugiados.

La desigualdad de ambas poblaciones, así como la diferencia de trato de las grandes organizaciones agudizó las tensiones. Por una parte creó un malestar creciente entre la población albanesa. Albania es mucho más pobre que Kosovo y fue invadida por una legión de organizaciones asistenciales y humanitarias que se volcaron en los kosovares, sin consideraciones con la población albanesa. Esto implicaba que en las salas de los hospitales un ciudadano kosovar podía estar bien atendido, mientras que otros albaneses que ocupaban una cama junto a él carecían de condiciones mínimas de atención. Había pacientes de primera y de segunda, 
como ocurría con los que vivían mezclados con familias albanesas, tan pobres o más que los refugiados. Unos recibían mucho y otros nada, según la nacionalidad.

A esta diferencia de trato se añadió la cesión de soberanía nacional albanesa en función de los intereses de la Alianza y el creciente deterioro de su infraestructura técnica y comunicativa. Las máquinas militares destruyeron las paupérrimas carreteras albanesas y las dejaron en condiciones impracticables, que crecían cada día. A esto se añadía una situación de abandono. Ahora que los kosovares vuelven, salen con ellos las organizaciones humanitarias, con el peligro de que crezca en Albania la sensación de que han sido utilizados mientras duró el conflicto y que ahora vuelven al olvido internacional, que se concentra en Kosovo. Ya veremos en qué quedan las promesas de la OTAN de integrar a Albania en los planes de reconstrucción de la zona, en buena parte deteriorada por el conflicto. Allí se percibe la agresividad contra los kosovares, que se hizo patente en los días en que comenzó el retorno, y el resentimiento contra los representantes de las organizaciones humanitarias y oficiales, que han estado de paso en Albania y ahora la dejan peor que antes. Había miedo a que la abundancia de recursos para la guerra se tornase ahora en cicatería y reservas a la hora de sufragar la reconstrucción.

Un espectáculo muy ambiguo es el que han ofrecido las organizaciones internacionales comenzando por las de las Naciones Unidas. Por un lado, hay que resaltar la ineficiencia y falta de previsión de ACNUR y demás organismos oficiales. Ni previeron la rapidez y radicalidad del exilio masivo de kosovares, ni han sido capaces de preparar el regreso. Cuando ya se había iniciado la vuelta de los refugiados, que se produjo de forma incontrolada y no planificada, todavía insistían en mantener los campamentos y afirmar que los refugiados no podían marcharse, cuando era evidente que los acontecimientos rebasaban esas posturas y consignas oficiales. La teoría de que no debían marcharse, seguía impidiendo ver los hechos: que el retorno ya había comenzado y era masivo. De esta manera no sólo no se preparó nada para ayudar al retorno, sino que se retardó la ayuda que podrían prestar las ONG allí presentes. Las críticas respecto a los organismos oficiales de las Naciones Unidas han sido constantes durante el tiempo de exilio kosovar: ineficiencia, distancia de la realidad, ineptitud para prever los problemas que podían plantearse a corto y medio plazo, incapacidad para resolver los problemas que se planteaban, arrogancia, a veces, por parte de los funcionarios de estas organizaciones etc. El problema de los refugiados es lo suficientemente 
grave y permanente como para que sea necesario un replanteamiento en profundidad de ACNUR y los demás organismos de las Naciones Unidas acerca de cómo deben trabajar en las zonas conflictivas. Sobre todo, hay que lamentar la incapacidad para conectar con la población local y sus instituciones, con objeto de evitar distorsiones e impedir que se les creen problemas. Falta una ética de las consecuencias, y por tanto una política responsable, ya que se piensa en la inmediatez de la intervención sin plantearse ni prever lo que puede acaecer a medio y largo plazo para las poblaciones afectadas.

¿Por qué se han marchado tan rápidamente los refugiados? Se han unido una serie de causas que han hecho que las acontecimientos se precipitaran. Por un lado, la cercanía de los campamentos y la euforia que se produjo tras la llegada de las tropas de la OTAN a Kosovo. Cuando llegaron a los campamentos, camino de Kosovo, se produjeron escenas que recordaban las escenas de la conocida película de Berlanga, ;Bienvenido Mister Marshall! Eran los salvadores y los liberadores y fueron recibidos con aclamaciones por los refugiados. Entre ellos no había lugar a la discusión occidental sobre la licitud o no de los bombardeos: eran los que les devolvían a la patria perdida. De ahí el éxodo del retorno a la tierra prometida, Kosovo, que se produjo un par de días después del paso de las tropas por los campamentos más cercanos a la frontera. A quince kilómetros de Kukes, el paso fronterizo más importante de Albania a Kosovo, estaba la patria y muchos de los que permanecieron en los campamentos de la frontera eran de pueblos y ciudades vecinos de la región kosovarcercana a Albania. Esta cercanía, unida a la mentalidad de clan familiar o tribu de muchos kosovares, hizo que la vuelta no fuera individual sino colectiva. Eran todos o la mayoría de los vecinos, parientes y familiares los que volvían juntos a algunos pueblos y pequeñas ciudades. Se produjo una auténtica histeria colectiva, un contagio en el que todos querían volver lo antes posible.

Había gente que aceptabas las recomendaciones de la ONU de retrasar la vuelta, dado el peligro de las minas, de los grupos serbios incontrolados y de la falta de seguridad en muchas zonas. Sin embargo, al ver a los parientes, vecinos o conocidos que se marchaban, cambiaban de parecer en cuestión de horas para unirse a los que retornaban. A esto se añadía la preocupación por llegarcon retraso. Querían ver cómo estaba la casa y la tierra que habían dejado, tener noticias de los familiares desaparecidos y asegurarse de que lo que quedaba no era objeto de 
la rapiña de los que llegaban. Muchos campesinos habían escondido cosas bajo tierra antes de la partida y tenían miedo de que otros las encontraran y se apoderaran de ellas. De ahí que los campamentos cercanos a la frontera se vaciaran en apenas una semana, mientras que los del centro y el sur lo hacían de forma gradual y más lentamente. En cualquier caso, la repatriación se produjo con rapidez inusitada mientras que las Naciones Unidas seguían afirmando que ésta no se produciría hasta más adelante, ignorando la realidad que rompía con las teorías. Los que quedaban eran los que menos medios tenían, los que carecían de dinero y transporte, o los minusválidos, enfermos y ancianos que lloraban su impotencia y se quedaban como últimos supervivientes de los campamentos. Encargarse del transporte de estas personas es una de las tareas que quedan para las organizaciones humanitarias. También aquí se constata la incapacidad de las Naciones Unidas y de las grandes ONG. Los que quedan son los más pobres de entre los refugiados, por tanto, los que notienen medios para desplazarse. Ellos deberían ser los sujetos preferentes de la ayuda internacional. Sin embargo, permanecieron semanas sin saber cuándo, cómo y por qué medios podrían repatriarse, cuando ya se había producido la vuelta masiva de los exilados. Las grandes organizaciones diferían indefinidamente concretar la fecha y los términos del regreso para estos grupos que no podían volver por sí mismos.

El panorama de las organizaciones es muy diverso y se puede constatar cómo hay una proliferación de agencias y ayudas, en las que se mezclan desde las perspectivas más altruistas e idealistas, hasta las más perniciosas, que han hecho negocio con la guerra y con los refugiados. Abundaban jovencitos, en su mayoría norteamericanos, que representaban a organizaciones con mucho dinero y que adoptaban posturas de autosuficiencia y de menosprecio, tanto respecto a los refugiados mismos como en lo que concierne a la población albanesa y la cooperación internacional. La tendencia de las burocracias a dominar sobre las instituciones a las que representan, se unía aquí a la arrogancia y falta de preparación de casi adolescentes que vivían una «aventura» entre los refugiados. Había demasiada gente que actuaba con una mentalidad colonial y primermundista: como si ya supieran de antemano lo que necesitaban los refugiados y sus necesidades, así como la mejor forma de responder a ellas, con un menosprecio claro del contexto kosovar y albanés en el que se desarrollaba la acción.

Algunos campos se han encontrado en situaciones lamentables, a veces incluso, 
con el abandono de las organizaciones que habían ayudado a montarlos. Hay grupos y organizaciones que se lanzan a la ayuda sin estar preparados para ella ni contar con los medios y personal necesario. Cuando luego surgen los problemas, se tiende a minimizarlos, ignorarlos o sencillamente a abandonar a la gente a su suerte. A esta irresponsabilidad se une la feroz competencia y el afán de protagonismo. Hay demasiada ansia de hacer cosas y aparecer en los medios y a esto se subordina la misma acción humanitaria. A esto se añade la política de los campos de refugiados: no sólo se convirtieron en un espacio para reclutarmilitantes y guerrilleros del UCK (el ejercito de liberación de Kosovo), sino también para la propaganda política en función de los intereses de los que controlan cada campo. No se puede dudar de que los campamentos han sido un semillero para la guerrilla del UCK, con la permisividad, cuando no la colaboración clara, de las autoridades de algunos campos.

También abundaba el «turismo de guerra o aventurero», que visitaba las zonas unos días «para hacer un informe» y que se convertían en una carga y un obstáculo para los que trabajaban allí de forma permanente. Hay que replantear el concepto de voluntarios y la forma de incorporarlos a las agencias humanitarias. Ha sido frecuente la afluencia de personas que llegaban dispuestas a trabajar, a veces por espacio de tiempo tan cortos como una semana, y que luego se iban defraudadas porque no tenían nada que hacer. O lo lograban gracias al esfuerzo de los equipos que allí existían por encontrarles algún tipo de tarea, aunque hubiera que crearla ex profeso para ellos. El procedimiento más útilen lo que respecta a los voluntarios es que éstos sean pedidos expresamente por los equipos que trabajan en los distintos lugares en función de las tareas que surgen o de los proyectos que se quieren llevar a cabo, en lugar de ser enviados por las oficinas centrales de las agencias, a veces desconociendo las condiciones reales de los sitios y equipos a los que se envían a estos voluntarios. Hay que asegurar también una estancia mínima de los voluntarios, ya que si no, son una carga y no una ayuda, y exigirles flexibilidad y capacidad de adaptación, dado que en estas situaciones de emergencia las situaciones cambian con rapidez y surgen necesidades no previstas.

La misma ayuda humanitaria revela gran cantidad de ambigüedades. Por un lado, ha habido una ayuda masiva de los países ricos europeos. Sin embargo, mucha de esa ayuda ha sido poco útil cuando no francamente nociva. Se han amontonado cantidades ingentes de productos higiénicos, de perfumería y objetos 
para el hogar que no tenían utilidad alguna para gente que vive en las tiendas. También creaban nuevas necesidades de consumo a personas que nunca han tenido esos productos y que no tendrán fácil prescindir de ellos cuando falten los que han suministrado las distintas agencias. Se ha enviado con generosidad pero con falta de criterio, lo cual ha dejado huecos importantes, por ejemplo, de ropa y calzado y ha generado una afluencia de cosas innecesarias, por ejemplo, cantidades masivas de agua mineral y envasada en sitios donde abunda el agua y no hay costumbre de beberla como un producto de consumo. Lo mismo ha ocurrido en lo que concierne a los alimentos, con una desproporción notable de artículos de primera necesidad (harina, aceite, arroz, etc) y otros abundantes más caros que responden a una sociedad de consumo, como por ejemplo, la ingente cantidad de chocolates y bombones, en su mayoría con fecha de caducidad muy próxima. La acumulación de bienes de consumo propios de la sociedad del bienestary la ausencia de productos básicos y urgentes para los refugiados han sido una constante. También aquí ha faltado una labor de información y de concientización de las organizaciones humanitarias a la hora de recoger y enviar ayuda a las zonas en conflicto. Esto se agudiza por el hecho de que hay una selva de ONG, muchas de ellas con mucho idealismo y buena voluntad pero con gran escasez de infraestructura y de medios técnicos y humanos, que se intenta suplir con voluntarismo y buena voluntad.

La misma forma de suministrar la ayuda ha generado problemas de envergadura. El más importante es el de la pérdida de cantidades ingentes de ayuda, a veces hasta dos tercios, que han ido a parar a las mafias locales y que han sido objeto constante de rapiña por parte de los mismos vigilantes y representantes de la autoridad. El problema ha sidomás la distribución y los medios de seguridad para que esto llegara a los afectados, antes que la recepción y acumulación de las ayudas. A esto se añade la desarticulación que han producidoen la economía local, por un lado, generando un importante mercado negro de productos (en su casi totalidad producto de los robos) que hacían la competencia al mercado local; por otro, generando un incremento de los precios de otros bienes, hasta tres o cuatro veces, dada la demanda masiva de las organizaciones y sus representantes. También ha repercutido en la economía el hecho de que las agencias asistenciales crearan canales de producción y abastecimiento al margen de las estructuras locales existentes, generando nuevas competencias y distorsionando el paupérrimo marco 
laboral de la población local. La improvisación, el individualismo y la falta de atención a la situación económica de la población que acogía a los refugiados han sido una constante, tanto en lo que concierne a las ONG como a las organizaciones oficiales. También aquí se detecta un grave problema que se repite a la hora de atender a situaciones coyunturales de emergencia que, sin embargo, son permanentes y previsiblemente van a durar mucho tiempo.

Algunas agencias y organismos humanitarios han colaborado intensamente los unos con los otros. En esto ha habido agencias ejemplares, pero también han rivalizado y han proliferado los celos y la competencia entre ellas para apuntarse tantos, para asumir el protagonismo, para salir en primer plano en los medios de comunicación. Ha habido demasiada lucha y deseos de apuntarse el primer tanto, en los que el prestigio de las organizaciones se ha puesto por encima de las necesidades de los refugiados. Y es que abundan los representantes de agencias que cobran sueldos abundantes y que ven en la ayuda humanitaria un gran negocio, en el que los refugiados son lo menos importante. La arrogancia de algunos funcionarios, que representaban poder y dinero para los refugiados y los albaneses, sólo es comparable a su falta de interés y de preparación. La proliferación de ONG en los distintos países facilita el descontrol y la afluencia de gente que busca aprovecharse del río revuelto de la guerra y los refugiados.

Además, las agencias acumularon gran cantidad de recursos, pensando en una larga duración de los campamentos, que luego no han podido utilizar por lo rápido y corto de la estancia de los refugiados fuera de Kosovo. Esto, unido a la falta de organización y de medios de transporte, ha hecho que buena parte de esos recursos se pierdan, vayan a parar a las mafias locales que han rapiñado campamentos y familias cuando se marchaban los refugiados, o sencillamente se deterioren y se pierdan. Las agencias se han encontrado con que han acumulado recursos que ahora no pueden devolver ni canalizar a los destinatarios y que no han sido capaces de dirigir eficazmente a otras zonas de refugiados necesitados, comenzando por el mismo Kosovo y siguiendo por otros campamentos no muy lejanos en África y en el próximo Oriente. Los camiones y contenedores descargados en la misma carretera para que los retornados escogieran lo que quisieran son un ejemplo del descontrol y la falta de organización de las agencias que tenían que distribuir la ayuda. El caos organizativo, la anarquía y proliferación de organizaciones y la incapacidad de planificación y organización de los organismos de las Naciones 
Unidas se han unido para hacer inefectiva buena parte de la ayuda recibida. La ayuda a los refugiados exige un replanteamiento, ya que no se trata de un problema coyuntural sino estructural y creciente, que constituye un reto para las Naciones Unidas y las Organizaciones no gubernamentales. Esta es una de las tareas que quedan para el futuro.

\section{Algunos interrogantes de futuro en Kosovo}

Se podría pensar que los problemas de los refugiados han quedado resueltos a partir del regreso. Por el contrario, ahora es cuando aparecen los mayores interrogantes. Por un lado, queda un país destrozado y roto. Ya veremos si la abundancia de dinero que hubo para la guerra, se da también parala reconstrucción. Ya sabemos que la opinión internacional es olvidadiza, que los gastos son abundantes y que dentro de unos meses Kosovo dejará de ser noticia. No sabemos si los compromisos contraídos serán respetados y en qué medida. De ello depende en buena parte el futuro de Kosovo, de Macedonia y Albania, de la misma Serbia y en general de todo el Sudeste europeo.

El problema de los refugiados se replantea, ahora con la minoría serbia, que asiste impotente a una oleada de incendios, asesinatos y saqueos sin que las autoridades militares de la OTAN puedan, a veces quizás no quieran, impedirlo. El drama de los refugiados continúa. La mayoría de los autores de las barbaries contra los kosovares han vuelto a Serbia. Queda una población minoritaria indefensa, en buena parte no culpable de las atrocidades de los grupos paramilitares serbios, algunos de ellos que ya fueron refugiados provenientes de Croacia y Bosnia y que fueron alojados en Kosovo por el gobierno de Milosevic y que ahora están abocados a otro exilio o a permanecer en medio de la población kosovar expuestos a la venganza y la revancha por el hecho de ser serbios. Los saqueos, venganzas indiscriminadas y crueldades comenzaron desde el mismo día del retorno y no se ve fácil ponerles un límite. Y es que el ideal de pluralidad, convivencia multicultural y respeto a las minorías resulta muy difícil de realizar cuando se han dado tantos niveles de opresión, de genocidios y de abusos humanos en la región. Y hay que reconocer que la situación es menos mala que la de Bosnia, por la rapidez con que se han desarrollado los acontecimientos bélicos (en comparación con la larga guerra que allí hubo), y por circunstancias externas que 
han limitado los daños. Por ejemplo, el hecho de que durante los meses de Abril e incluso Mayo hubiera condiciones metereológicas adversas y grandes nevadas no sólo hizo que la deportación de los refugiados se hiciera en condiciones más penosas, sino que favoreció el que no se pudieran implantar las minas antipersonales a gran profundidad, con lo que al desaparecer la nieve quedaban más al descubierto y era más fácil su localización.

¿Quién desarmará y controlará a la UCK, que propugna la independencia del país y el mantenimiento del armamento como garantía de ello? La independencia aparece como inevitable si se atiende al hecho de que la minoría serbia existente (en torno al $15 \%$ de la población) disminuye drásticamente por la huida a Serbia. A esto se añade el hecho de que la convivencia entre kosovares y serbios se hace casi imposible a partir de las masacres, fosas comunes y atrocidades que ha generado la limpieza étnica. Se necesitarán decenios para asumir lo ocurrido, aprender a perdonar y asumir una coexistencia a la que están condenados por ser vecinos. Por otro lado, la independencia de Kosovo, tras previsibles años de protectorado internacional, también se convierte en un interrogante desestabilizador para la región. Comenzando por Albania, ya que todos forman parte de un único pueblo. Siguiendo por Macedonia, estado artificial con una importante minoría albano-kosovar, de casi un cuarto de la población, con otra gran representación de población serbia o filoserbia y otra parte más cercana a los griegos, que nunca han escondido sus apetencias y reservas respecto al nuevo Estado de Macedonia. A esto se añade el problema de Montenegro, que puede ser la nueva zona de guerra en los Balcanes, y el problema de las importantes minorías, por ejemplo húngaras o rumanas, que existen dentro de estados que tienen unas fronteras políticas que dividen las etnias y las poblaciones.

Los Balcanes son una mezcla explosiva en la que coexisten etnias, religiones, culturas, historias, alfabetos y estados dispares. No hay para ellos otra solución que la multiculturalidad, la sociedad mestiza, la integración en bloques internacionales y la conjunción de la pluralidad con la pertenencia común. Pero todo esto se ha complicado con las guerras que han asolado la región en la última década. La de Kosovo ha sido la última, pero puede no serlo y los problemas que había antes de la guerra no se han resuelto con la intervención de la OTAN. Es verdad que se ha parado la limpieza étnica, que se ha posibilitado la vuelta de los desplazados y que se ha puesto un límite al poder de un régimen fascista como el 
de Milosevic. Sin embargo, casi todo queda pendiente de lo que ocurra en el futuro, ya que los problemas se han aplazado pero no se han resuelto y en algunos extremos se han agravado. Y es que la guerra ha sido una respuesta tardía, en buena parte deslegitimada en su forma y en su contenido, y con la amenaza de ser ineficiente e improductiva a medio y largo plazo. La sensación de perplejidad y de impotencia aumenta cuando uno se pregunta qué hubiera pasado si no se interviene, ya que algo había que hacer, aunque lo que se ha hecho y la forma de hacerlo plantee serios interrogantes.

Por eso es incomprensible la postura maniquea de los que presentan la batalla como una mera lucha de buenos y malos. No hay duda ninguna del significado opresor, fascista y genocida, del régimen de Belgrado. Pero se olvida con facilidad que ese mismo régimen fue legitimado y aceptado por los estados occidentales en el pasado reciente. Y queda pendiente una posibilidad perversa, la de que la OTAN se convierta en la alternativa a la ONU, que la reforma de ésta última se difiera indefinidamente y que la guerra de Kosovo inaugure una nueva tipología de guerras, en la que el enfrentamiento de los ejércitos se sustituya por la destrucción de un país y la abundancia de víctimas entre la indefensa población civil. Estos son algunos de los interrogantes que permanecen después de la guerra de Kosovo.

Y quedan los refugiados, que no son coyunturales sino estructurales, que permanecen en Kurdistán, en los Grandes Lagos, en Sudán, en Indochina, en Palestina o algunas regiones de América Central y en otras partes del mundo. Son las víctimas permanentes de los conflictos y guerras locales que siguen dándose en el planeta. Constituyen el gran reto para las ONG, organizaciones humanitarias, iglesias y gobiernos. Son silenciados e ignorados por la opinión pública que sólo se acuerda de ellos puntualmente, como ocurre ahora con los kosovares, cuando las peores consecuencias de las múltiples guerras locales logran pasar a los titulares de los medios de comunicación. El tiempo dirá si los refugiados kosovares desaparecerán, gracias al esfuerzo internacional por pacificar y reconstruir los Balcanes, o si se sumarán a esta multitud de desheredados, que son los parias de 